\title{
Role of diet in treating atopic eczema: dietary manipulation has no value
}

\author{
Roger Allen
}

The eczema that so often occurs as part of the atopic state usually has its onset between the ages of 4 and 24 months. Thus the affected infant is born healthy and becomes ill so distressed mothers naturally ask what they have done to harm their child. Environmental factors probably do play a part in the expression of eczema as there is, for example, a low incidence in poor tropical countries ${ }^{1}$ and the highest incidence in Britain is in socioeconomic group I. ${ }^{2}$ Understandably therefore dietary factors come under scrutiny, although it is clear that they are not the fundamental cause of the problem. Even the most enthusiastic advocates of dietary manipulation claim that it is a suitable approach in only about $10 \%$ of children with eczema. ${ }^{3}$

\section{Adverse reactions to food}

If diet were significant there are two mechanisms by which it could exert an influence: it might be in some way deficient or the eczema could constitute an adverse reaction to something eaten. For both mechanisms it is easy to argue logically that breast feeding should be beneficial, but, although this argument was first put forward over 50 years ago, ${ }^{+}$there is still no persuasive evidence that it is correct, with many trials producing contrary evidence. ${ }^{56}$ During the same decade Hansen claimed that infantile eczema was associated with a deficiency of the newly discovered essential fatty acids. ${ }^{7}$ This hypothesis has not, however, stood the test of time, although it has had something of a resurrection with the suggestion that patients with atopic eczema may be deficient in $\Delta-6$ desaturase. ${ }^{8}$ This enzyme converts linolenic acid into $\gamma$-linolenic acid, allowing its further metabolism and incorporation into the phospholipid of the cell wall. $\gamma$-Linolenic acid is not plentiful in a normal diet but it is found in breast milk ${ }^{9}$ and oil from the seeds of the evening primrose (Oenothera biennis). ${ }^{10}$ Trials of the oil as a dietary supplement in atopic eczema have yielded conflicting results $^{112}$ so that currently there is no conclusive evidence of its benefit.

Many people, both lay and medical, who advocate dietary manipulation assume that eczema is being caused by a food "allergy." Unfortunately the subject of food associated disease is bedevilled by unsubstantiated claims and often a complete misuse of the word "allergy," which should be restricted to describing only those reactions in which an immune response can be shown. Otherwise the term "adverse reaction" or "intolerance" should be used. ${ }^{13}$ That breast feeding does not prevent the development of true food allergy has been clearly shown in a study following for seven years 1753 children fed initially on breast, soy, or cows' milk: the occurrence of allergy was similar in each group. ${ }^{1+}$ The only immunological reaction that has been unequivocally shown to occur from food is a type I reaginic response mediated by IgE. Its characteristics are swelling like angio-oedema of immediate onset around the lips, burning of the mouth and throat, widespread urticaria, and an immediate recurrence on challenge with the offending substance. Undoubtedly children with atopic eczema do show a high incidence of true food allergy of this type and many have eczema ${ }^{15}$; the two conditions are, however, separate and there is neither a diagnostic nor therapeutic problem as the offending food is easily identified and excluded from the diet: indeed even infants will spit it out because of the intense burning sensation it often causes in the mouth.

\section{Can IgE mediated reactions result in eczema?}

No evidence exists that a response mediated by IgE gives rise to an eczematous type of eruption. ${ }^{13}$ Thus the hypothesis in infants who subsequently develop eczema that the gut wall provides a defective barrier against the absorption of macromolecules that give rise to IgE antibodies which in turn cause eczema seems to be flawed because eczema has never been shown to occur. In an investigation of 541 patients with atopic dermatitis 84 gave histories of cutaneous symptoms related to food, but whereas in the group with urticaria a good correlation was found among the history, the results of radioallergosorbent tests, and the results of a challenge, no such correlation was found in those who believed that their eczema was made worse. Unfortunately most studies of diet in eczema rely heavily on the apparent improvement after excluding an item, whereas the true test of an adverse reaction is the development of an exacerbation on double blind challenge..$^{13}$ Theoretically an adverse reaction to food may be caused by a non-immunological mechanism. The commonest of these is psychogenic, ${ }^{13}$ which in the case of children with atopic eczema afflicts their parents. Local irritation of the lips can certainly be caused by some foods, such as tomatoes, citrus fruit, and cheese, but as with the reactions mediated by IgE, identification and exclusion does not present difficulties, although misinterpretation of the reaction

continued on page 1460

\section{EDITORIAL COMMENT}

The diagnosis of type I contact urticaria mediated by IgE is straightforward. Identifying a clear relation between one particular type of food and atopic eczema is much more difficult. There is very limited evidence in the form of double blind rechallenge that certain foodstuffs can affect atopic eczema. Such a relation might, however, be the exception rather than the rule. In most cases in which diet has been implicated in causing atopic eczema rechallenge has not taken place, although the double blind crossover
University Hospital, Nottingham NG7 2UH Roger Allen, FRCP, consultant dermatologist study described by Dr Atherton certainly gives suggestive evidence that in some patients diet may be implicated. Both authors emphasise that dietary manipulation may result in inadequate nutrition and therefore does not constitute a form of management that is without risk. Although the case remains unproved, when conventional management has not succeeded a place for dietary manipulation seems reasonable, but under careful supervision. As with all other forms of treatment if there is no clear improvement then the diet should revert to normal. - PETER RUBIN, professor of therapeutics, University Hospital, Nottingham NG7 2UH 


\section{Controversies in \\ Therapeutics}

David J Atherton

continued from page 1458 vocative role of a wider variety of foods. Hathaway and Warner reported their experience in a group of $\mathbf{4 0}$ eczematous children who were responsive to diet. ${ }^{7}$ Those not helped by simple empirical diets had been given increasingly restrictive diets until improvement occurred. Seven of the 40 children responded to excluding egg and milk alone, 30 responded to more restricted diets, and three improved only when given an elemental feed. An attempt was then made to identify the provocative foods, checked by double blind challenges. In addition to milk and eggs, commonly implicated foods included citrus fruits, colourings and preservatives, nuts, fish, wheat, tomatoes, lamb, chicken and soya, showing that unresponsiveness to a simple diet does not necessarily exclude a provocative role for foods in individual patients.

\section{Conclusions}

The evidence from published studies and our own experience, suggests that a proportion of children with atopic eczema will benefit from dietary elimination of selected foods. Several foods may need to be excluded, and currently available tests will not reliably identify them. The proportion of children likely to benefit is probably not less than a quarter and not greater than a half. Whether this rate of response could be improved by developing more accurate methods for identifying provocative foods is an important but unanswered question. How long the benefit of dietary modification may be maintained is also unclear. Our practice is to consider a trial of a simple, empirical exclusion diet in any children below the age of 8 years in whom adequate topical treatment has been insufficiently beneficial. ${ }^{8}$ Children with atopic eczema should not be treated with diets as a matter of routine. Elimination diets should not be continued long term without good evidence of benefit, and their nutritional sufficiency should be carefully checked.

1 Sampson HA. Role of immediate food hypersensitivity in the pathogenesis of atopic eczema. F Allergy Clin Immunol 1983;71:473-80.

2 Sampson HA, Jolie PL. Increased plasma histamine concentrations after food challenges in children with atopic eczema. $N$ Engl $\mathcal{H}$ Med 1984;311:372-6.

3 Sampson HA, Albergo R. Comparison of results of skin tests, RAST, and double-blind, placebo-controlled food challenges in children with atopic dermatitis. F Allergy Clin Immunol 1984;74:26-33.

4 Pike M, Atherton DJ. Atopic eczema. In: Brostoff J, Challacombe SJ, eds. Food allergy and intolerance. London: Baillière Tindall, 1987:583-601.

5 Atherton DJ, Sewell M, Soothill JF, Wells RS, Chilvers CED. A double-blind controlled crossover trial of an antigen-avoidance diet in atopic eczema. Lancet 1978; ; :401-3.

6 Neild VS, Marsden RA, Bailes JA, Bland JM. Egg and milk free exclusion diets in atopic eczema. Br f Dermatol 1986;114:117-23.

7 Hathaway MJ, Warner JO. Compliance problems in the dietary management of eczema. Arch Dis Child 1983;58:463-4.

8 Atherton DJ. Diet and atopic eczema. Clin Allergy 1988;18:215-28.
Roger Allen

continued from page 1459 may persuade the parents to exclude unnecessarily from the diet any prepared foods containing such ingredients.

Food additives have also been blamed for exacerbating eczema, but as Lessof et al pointed out there is no logic in considering additives as a unified group, such is the wide range of chemicals included under this heading. ${ }^{15}$ The dye tartrazine has been incriminated most frequently in view of its effect in urticaria, but, although it releases histamine, a survey of the prevalance of reactions to food additives in 18582 people failed to identify one in whom the challenge produced eczema. ${ }^{16}$

\section{Conclusion}

Dietary factors are not the cause of atopic eczema, and I think that any substantial evidence that they cause it to worsen is lacking. There is a risk that exclusion diets inexpertly used in children will in providing inadequate nutrition do harm, ${ }^{17}$ and I therefore see no grounds on which to recommend manipulating the diet as a form of treatment and strongly discourage my patients from doing so.

1 Lynch NR, Medouze L, Di Preso-Fuenmayor MC, Verde O, Lopez RI, Malave C. Incidence of atopic disease in a tropical environment: partial independence from intestinal helminthiasis. $\mathcal{F}$ Allergy Clin Immunol 1984 73:229-33.

Anonymous. Breast feeding and atopic eczema [Editorial]. Br Med f 1983;287 775-6.

3 Atherton DJ. The role of foods in atopic eczema. Clin Exp Dermatol 1983;8:227-32.

Grulee CG, Sanford HN. The influence of breast and artificial feeding on infantile eczema. I Pediatr 1936;9:223-5.

5 Bonfazi E, Garofalo L, Monterisi A, Menghini CL. History of food allergy, RAST and challenge tests in atopic dermatitis. Acta Derm Venereol (Stockh) 1980;92:91-3.

6 van Asperen PP, Kemp AS, Mellis CM. Relationship of diet in the development of atopy in infants. Clin Allergy 1984;14:525-32.

7 Hansen AE. Essential fatty acid deficiency in atopic eczema. Proc Soc Exp Biol Med 1933;31:160-1.

8 Manku MS, Horrobin DF, Morse N, Wright S, Burton JL. Essential fatty acids in the plasma phospholipids of patients with atopic eczema. $B r f$ Dermatol 1984;110:643-8.

9 Gibson RA, Kneebone GM. Fatty acid composition of human colostrum and mature breast milk. Am f Clin Nutr 1981;34:252-7.

10 Hudson BJF. Evening primrose (Oenothera spp) oil and seed. fourmal of the American Oil Chemists Society 1984;61:540-3.

11 Wright S, Burton JL. Oral evening primrose oil improves atopic eczema. Lancet 1982; ; 1120-2.

12 Bamford JTM, Gibson RW, Renier CM. Atopic eczema unresponsive to evening primrose oil. F Am Acad Dermatol 1985;13:959-65.

13 Pearson DJ. Food allergy, hypersensitivity and intolerance. $f R$ Coll Physicians Lond 1985;19:154-62.

14 Halpern SR, Sellars WA, Johnson RB, Anderson DW, Saperstein S, Reisch JS. Development of childhood allergy in infants fed breast, soy or cow's milk. F Allergy Clin Immunol 1973;51:139.

15 Lessof MH, Wraith DG, Merrett J, Buisseret PD. Food allergy and intolerance in 100 patients-local and systemic effects. Qf Med 1980;195: intolerance. $259-71$.

16 Lessof $M H$. Adverse reactions to food additives. $f R$ Coll Physicians Lond 1987;21:237-40.

17 Caputo RV, Frieden I, Krafchik BR, et al. Diet and atopic dermatitis. $\mathcal{f}$ Am Acad Dermatol 1986;15:543-5.

\section{ANY QUESTIONS}

Sodium is said to increase the urinary excretion of calcium, and osteoporosis has been attributed partly to the salt content of the Western diet. If so can sodium bicarbonate be justified as an ingredient of a calcium supplement?

There is good evidence both in man and in rats that increased sodium chloride intake increases urinary calcium excretion and is associated with raised serum concentrations of parathyroid hormone. The initial effect is mediated at a renal level, where tubular reabsorption of calcium is closely linked to that of sodium. Susceptibility to osteoporosis is determined by age, sex, race, and a host of local bone and systemic factors, which include urinary calcium excretion and calcium intake. ' While salt loading leads to osteopenia in animals, ${ }^{2}$ there is as yet no direct evidence in man linking sodium intake to accelerated bone loss. It is illogical, however, to prescribe calcium in a preparation that is likely to affect adversely calcium balance. Furthermore, sodium intake in Western communities is excessive. It probably contributes to an increased blood pressure with age ${ }^{3}$ and is likely in salt sensitive individuals to raise blood pressure in the short term. It seems unwise, therefore, to prescribe sodium bicarbonate as an ingredient of a calcium supplement when alternative preparations are available. - I PERRY, research registrar, D G BEEVERS, consultant physician, Birmingham

1 Laurence GR. Local and systemic factors in the pathogenesis of osteoporosis. N Engl I Med 1988;318:818-28.

2 Goulding A, Everitt HE, Cooney JM, Spears GFS. Sodium and osteoporosis. In: Wahlqist ML, Truswell AS, eds. Recent advances in clinical nutrition. London: John Libbey, 1986:99-108.

3 Intersalt Cooperative Research Group. Intersalt: an international study of electrolyte excretion and blood pressure. Results for 24 hour urinary sodium and potassium excretion. $\mathrm{Br} \mathrm{Med} \mathcal{J}$ and blood pressure. 